\title{
Arbor
}

\section{La naturalización de la mente}

\author{
Jesús Martínez Velasco
}

Arbor CLX, 629 (Mayo 1998), 35-67 pp.

El artículo plantea la posibilidad de ofrecer acerca de los fenómenos y eventos mentales una concepción naturalista de análogo tenor a la que se ofrece de cualquier otro fenómeno físico o biológico. Aunque esto no supone pasar necesariamente por el reduccionismo, sí que constituye éste una de las posibilidades. En cualquier caso, la filosofía de la mente no puede ser prisionera de una tradición que exige un lugar separado y autónomo para la psicología del sentido común, y debe abrirse y reconstruirse como filosofía de la ciencia, en cuyo ámbito los eventos mentales no pueden situarse en un nivel diferente del natural, porque ello supondría viciar de raíz el origen biológico de cualquier actividad humana, incluida la actividad mental. Dicho lo cual, es necesario aceptar que no se conoce todavía lo suficiente acerca del funcionamiento de las estructuras físico-cerebrales implicadas en la actividad cognitiva, pero éste parece ser, a pesar de todo, el camino más correcto.

\section{Introducción}

En su obra La Actitud Intencional Dennett dice que los filósofos deben dejar de imaginar teorías sobre la mente, hechas desde el laboratorio de su imaginación, y tienen que mirar por la ventana para familiarizarse con las investigaciones efectuadas en el campo de las neurociencias y de las ciencias conexas. En parecidos términos se expresa Patricia Churchland cuando dice que muchos problemas sobre la mente que han estado planteados desde los griegos y que en la actualidad siguen sin resolver (como por ejemplo, la naturaleza del conocimiento, la forma de representar el mundo, la conciencia, el yo, la inteligencia, 
etc), necesitan ser tratados desde otros supuestos teóricos y metodológicos si se quiere que tales asuntos se orienten en una dirección que haga posible una aproximación más racional a su todavía hoy lejana solución. Por eso, resulta inevitable adentrarse en el conocimiento de la estructura y del funcionamiento cerebral del que dependen actividades como la percepción, la representación, la conciencia, etc, y que no se puede especular ignorando esos datos, como no se puede especular sobre el espacio y el tiempo, sin conocer la teoría de la relatividad, ni sobre la vida, sin conocer la biología molecular. No obstante, se producen resistencias a aceptar que los problemas relativos a la mente deban circunscribirse al marco estrecho de una visión científica, porque, por su propia naturaleza, parecen escapar y estar más allá de cualquier supuesto téríco y metodológico impuesto por la ciencia. Se dice que cosas ontológicamente desiguales no pueden tratarse ni técnica ni procedimentalmente de forma igual. No cabe el reduccionismo ni ontológico ni metodológico, porque en el universo existe una multiplicidad de seres, cuyas naturalezas íntimas difieren sustancialmente unas de otras. Algunos de estos seres, como, por ejemplo, los eventos mentales, pertenecen a un orden de realidad que no se rige por las mismas leyes por las que se rigen otros acontecimientos pertenecientes al orden natural.

¿Por qué esta diversidad ontológica no puede ser compatible con una naturalización general del problema que nos ocupa? La dificultad e incluso la imposibilidad actual de dar una solución a los problemas de la mente no tiene por qué autorizar a situar la vida mental más allá de la vida natural. ¿Será necesario, tal vez, como dice Penrose, ampliar nuestra imagen científica del momento para que se pueda abordar el estudio de la conciencia desde una perspectiva científica? ${ }^{1}$. Lo que parece claro es que una visión del mundo que prescinde de la mente consciente no puede llegar nunca a proporcionar una descripción auténtica del universo, ya que dejaría fuera algo (la conciencia) que forma parte del mundo natural.

La perspectiva naturalista de la mente pretende situar el cerebro humano, al igual que la ciencia y la cognición, dentro del proceso biologico evolutivo en el marco general de las necesidades fundamentales de supervivencia. La cognición y la conciencia no se elaboran en un mundo platónico, sino en un mundo de competición darwiniana. Como dicen Changeux y Dehaene, el cerebro hay que concebirlo como un sistema evolutivo, más que como una máquina estática, que forma parte de un organismo que pertenece a una especie que ha evolucionado en el tiempo y sigue haciéndolo, y cuya complejidad es tal que se le 
puede considerar que evoluciona según un orden de complejidad creciente $^{2}$. Semejante sistema, a cualquier nivel, no sería indiferente a la naturaleza de los procesos cognitivos. Estaría, más bien, impregnado de conocimientos, desde la organización de su genoma hasta sus intenciones más efimeras. Una visión naturalista de la mente o, como F. Dretske llama, la tesis representacional o el naturalismo representacional, permite situar el problema de lo mental en el contexto que le es propio, a saber, el universo natural, en cuyo marco la subjetividad puede ser estudiada objetivamente ${ }^{3}$. Se desmitifica así la introspección, porque el conocimiento de la propia mente no requiere un "ojo" interno que observe el mecanismo de relojería de la misma. Proporciona una respuesta, biológicamente plausible, a los problemas sobre la función o propósito de la conciencia. Estos beneficios, y más, derivan de concebir la mente como la cara representacional del cerebro.

Como la manipulación y uso de las representaciones es la tarea principal de la mente, intentar comprender las representaciones y su base naturalista en el contexto de las neurociencias es algo, como dice Patricia Churchland, particularmente revolucionario, pero permitirá una comprensión más profunda de la mente ${ }^{4}$. Parece obvio, desde este punto de vista, que cuanto mayor y mejor sea nuestro conocimiento de las estructuras cerebrales, eso nos obligará a una reformulación de nuestras ideas concernientes a la conciencia, al conocimiento, al yo, etc. Mientras tanto, la convergencia entre las neurociencias, la psicología y la inteligencia artificial puede procurarnos una mejor comprensión de los principios de la representación, aunque para ello sea necesario abogar, como dice Stengers, por un concepto más débil de ciencia capaz de integrar en sí no sólo la explicación, sino también la interpretación y la comprensión ${ }^{5}$.

Stengers no se muestra de acuerdo con la rigidez de los protocolos que garantizan la cientificidad. $\mathrm{O}$, como dice Penrose, "tal vez para acomodar el misterio de la mente, sea necesario ampliar nuestro concepto de ciencia, pero no hay razón para romper con los métodos de la ciencia", porque sólo del uso de los métodos de la ciencia y de las matemáticas se ha conseguido un progreso real en la comprensión del comportamiento del mundo ${ }^{6}$. Por tanto, los interrogantes a los que tendremos que responder y, hasta donde sea posible, justificar, son, por un lado, si la ciencia, además de ocuparse de los atributos materiales del universo, puede ocuparse también de nuestra existencia mental; por otro, si podremos llegar a comprender algún día el misterio de las mentes y, en concreto, si la conciencia está más allá del dominio de la investigación científica, o si ésta será tan potente que pueda 


\section{Jesús Martínez Velasco}

resolver el problema de la existencia del yo consciente. Como todos sabemos, se han dado múltiples respuestas, algunas contradictorias entre sí, otras, producto más de simples especulaciones imaginativas y deseos que de una investigación racionalmente fundada y científicamente justificada.

\section{Neurociencia y filosofía}

Aunque no es una novedad de los últimos tiempos, sí se está produciendo en las décadas recientes avances muy significativos en todo lo referente al conocimiento del funcionamiento de las estructuras cerebrales: en el campo de estudio de las células nerviosas aisladas y sus componentes moleculares, y en el estudio de la anatomía comparada en animales superiores y el hombre. Todo ello está proporcionando aportaciones muy importantes sobre la complejidad de la organización del cerebro adulto y su morfogénesis, y dando lugar a una mejor aproximación a las posibles conexiones entre cerebro y cognición. A partir de aquí se ha creado un programa radical según el cual la ciencia de la vida mental estaría reducida a las ciencias neurales y las doctrinas de la psicología del sentido común deberían ser eliminadas. En febrero de 1996, la propia Revista Arbor dedicó un número monográfico al tema de Neurociencia y Pensamiento, compilado por Francisco Mora, el mismo autor que en 1995, había editado en Alianza Universidad el libro El problema cerebro-mente.

Con excepciones, ésta es la doctrina mayoritariamente aceptada por los neurocientíficos y neurofilósofos, algunos de cuyos máximos exponentes son hoy Paul y Patricia Churchland, que representan una de las posiciones extremas, aunque recientemente matizada, del materialismo: la del materialismo eliminativo, según la cual, la psicología popular es una teoría de lo mental radicalmente falsa, como lo es la teoría del flogisto en química; y la concebían como falsa, porque creían inicialmente, en su versión más extrema, que las entidades simbólicas y las propiedades de los estados cognitivos que postula la teoría representacional de la mente y la psicología popular simplemente no existen. Al principio (luego matizarán sus posiciones), los eliminativistas, como creían que no había nada en los estados mentales que correspondiera a lo que para ellos postulaba la psicología popular, se consideraba que no existían y que nuestra psicología del sentido común era simplemente un mito. En el libro anteriormente citado, Mora dice que acepta la tesis de P. Churchland y de Sejnowski, y afirma que 


\section{La naturalización de la mente}

«el materialismo, como lo es la revolución darwiniana, es la hipótesis de trabajo más segura" ?.

Sin embargo, plantear el problema de las relaciones entre neurociencias y filosofía exige partir de la duda de si las neurociencias son capaces de dar una explicación completa de los fenómenos mentales o, por el contrario, hacen aparecer en su seno zonas de sombra. Esta duda, que parece inevitable, hace que nos formulemos preguntas tales como hasta qué punto la experiencia mental subjetiva puede explicarse a partir de neuronas, corrientes eléctricas, etc. O, cómo saber si las investigaciones experimentales sobre el cerebro tienen por horizonte la reducción que propone la teoría materialista de la mente. A este respecto, R. Pascual afirma que «a pesar de sus aspectos criticables, hay que reconocer que la física reduccionista ha alcanzado éxitos impresionantes, logrando formular teorías de gran simplicidad y belleza conceptual que permiten describir y predecir con gran precisión los resultados experimentales", aunque introduce más adelante una duda respecto a su aplicación a sistemas más complejos, como es el caso de los organismos y problemas cerebrales ${ }^{8}$.

\subsection{Breve repaso histórico sobre el materialismo}

En la antigüedad nos encontramos ya con respuestas que expresan algunas de las posturas contrarias que hoy día se sig!sen manteniendo, aunque desde marcos conceptuales muy diferentes. En un extremo se encuentran los antirealistas extremos (o cognitivistas puros) y en el otro los realistas extremos (o materialistas). En ambos casos, estamos ante una actitud reduccionista.

Platón habla contínuamente de forma despectiva de los materialistas y considera al alma como la que "mantiene y pilota la naturaleza de todo el cuerpo para hacerla vivir y moverse». Es una especie de fuerza que gobierna el cuerpo, siendo éste una tumba o cárcel para ella ${ }^{9}$. El alma constituye la parte más elevada del hombre, cuyas actividades culminan en la intelección que, a su vez, constituye la parte más noble de ella. El alma equivale esencialmente a la mente, al intelecto, que está en clara oposición con el cuerpo y separada de él, como el mundo de las formas lo está del mundo físico.

Aristóteles, a través de las nociones de materia y forma, por medio de las cuales pretende expresar adecuada y dinámicamente la relación entre alma y cuerpo, se mantiene en un punto equidistante de un materialismo que reduce el alma a una resultante del cuerpo, y de 
un espiritualismo, que rompe la solidaridad entre alma y cuerpo, a pesar de que no rechaza, de forma radical, la existencia separada del alma ni su supervivencia. En ambos casos, se muestra una superioridad del alma inmaterial sobre la materia, idea que se transmitirá y se defenderá más tarde por parte de la totalidad de pensadores cristianos.

No obstante, los atomistas, Epicuro y, en el mundo latino Lucrecio, sistematizan la visión materialista del hombre. Para Demócrito, el alma es un cuerpo y, al igual que el sol y la luna, está constituida por "átomos lisos y redondos» ${ }^{10}$. En términos semejantes se expresa Epicuro para quien «el alma es un cuerpo compuesto de partículas sutiles, que se encuentra esparcido por todo el compuesto que constituye nuestro cuerpo" ${ }^{11}$, y Lucrecio, que en el De Rerum Natura dice que el "alma es una materia sutil, formada por elementos minúsculos...." ${ }^{12}$.

Durante la Edad Media, los sistemas materialistas fueron ignorados, porque existía un cristianocentrismo generalizado y el materialismo se ha presentado como el eterno antagonista de la religión.

A partir del s. XVII comienzan a aparecer en mayor número los que se proclaman a sí mismos materialistas: Hobbes, Gassendi, La Mettrie, Diderot, Helvetius, D'Holbach y Cabanis. El denominador común a todos ellos es la afirmación de que la materia puede pensar $y$, por tanto, existe una correlación rigurosa entre los procesos psicológicos y los fenómenos orgánicos. Se defiende la existencia de un materialismo naturalista basado en la experiencia. Todos parten de la idea de que los fenómenos humanos, cualesquiera que sean, deben ser estudiados desde la perspectiva de las ciencias naturales.

Los avances en la investigación del sistema nervioso comenzaron a aparecer sobre todo en la segunda mitad del s. XIX con los progresos en el conocimiento de la anatomía del sistema nervioso y las localizaciones cerebrales. Desde mediados de nuestro siglo, filósofos como Feigl, Smart, Place, Armstrong, Ryle, Lewis, etc. han reafirmado el materialismo en el debate concerniente a las relaciones mente/cerebro. A ellos se han sumado la mayoría de neurocientíficos, sin que se pueda decir que exista una postura uniforme respecto a este problema, antes bien, el materialismo contemporáneo reagrupa a un conjuunto complejo de corrientes llenas a veces de contradicciones y conflictos que está muy lejos de constituir un grupo monolítico: la teoría de la identidad, el materialismo eliminativo, el funcionalismo, el conductismo, etc. con todas las versiones y ramificaciones diversas de un tronco común que es el fisicalismo o materialismo.

La neurociencia, la teoría de la computación y el conductismo son, en efecto, formas de aproximación al problema de la explicación de 
los fenómenos cognitivos y conscientes desde una perspectiva materialista. Algunos seguidores de estas corrientes adoptan posturas radicales; otros, en cambio, suavizan sus punos de vista. En el primer caso, estarían hoy día J.P. Changeux (El Hombre Neuronal), el neurocientífico americano G.M. Edelman y los neurofilósofos P.M. y P.S. Churchland. Entre los segundos, estaría M. Bunge, que defiende el punto de vista de un materialismo psiconeural emergentista, ya que, a su juicio, una ontología fisicalista no cuadra con la variedad de la realidad, aunque él sigue considerándose materialista. P. Engel ${ }^{13}$, sostiene que es necesario situarse en un punto intermedio entre los conservadores de la psicología popular y los eliminativistas, ya que no existen razones para sacar conclusiones tan radicales en uno $u$ otro sentido, ni para ser un antirealista extremo ni un extremo realista. Rechazar el eliminativismo no implica ni supone aceptar nociones extrañas de la psicología popular, ni que ésta baste para la explicación científica. Se manifiesta, pues, en contra de cualquier tipo de reduccionismo, bien de tipo cognitivista o de corte puramente realista.

\subsection{Reduccionismo Neural}

La tesis reduccionista ha sido desde siempre objeto de disputa. Algunos han creído ver en la reducción metafísica una razón importante para rechazar el materialismo, porque la consideran una aproximación errónea, mezquina y ciega para la riqueza de fenómenos que ocurren en la vida psicológica de los individuos. Para éstos no resulta razonable una reducción de todos los fenómenos psicológicos a fenómenos neurobiológicos y computacionales. Lo que los filósofos llaman "qualia", es decir, los diferentes caracteres cualitativos subjetivos que ocurren en nuestras sensaciones se ha creido por algunos ya desde antiguo y todavía que estarían más allá de cualquier explicación materialista o reducción. Lo mismo sucede con todo lo referente al contenido semántico y a la intencionalidad de nuestros pensamientos. Por qué pensar, como decía Fodor, que la psicología debe ser reducida a la neurobiología. Para los Churchlands, ésta es una posición que tiene que ser resistida y ven la reducción como un acontecimiento normal en la historia de la ciencia y, además, la reducción auténtica, cuando se logra, es una buena cosa ${ }^{14}$.

I. Stengers se pregunta, no obstante, cómo saber si las investigaciones experimentales sobre el cerebro tienen por horizonte la reducción que propone la teoría materialista de la mente. En concordancia 
con la tesis básica de Penrose cree que las teorías materialistas de la mente, lejos de asumir las implicaciones de un programa científico efectivo, parecen perseguir un fantasma de ciencia que resulta ser hoy muy poco pertinente. Ella, como ya hemos dicho, se muestra partidaria de un concepto más débil de ciencia, capaz de integrar en sí, no sólo la explicación, sino también la comprensión y la interpretación. Está, pues, en contra de la rigidez de los protocolos que garantizan la cientificidad y, de acuerdo con Penrose, en la necesidad de un cambio importante en nuestras leyes físicas básicas, porque si queremos abordar el estudio de la vida mental desde una perspectiva científica, será necesario cambiar nuestra imagen científica actual.

Sea como fuere, el debate acerca de la relación mente/cerebro está inclinado hoy en favor del materialismo. En el campo de las neurociencias, el espiritualismo es hoy día una metafísica en su mayor parte abandonada. Sin que esto suponga prejuzgar a favor del principio de autoridad, la mayoría de los neurocientíficos y de los especialistas en ciencias cognitivas está de acuerdo en decir que el cerebro es el «órgano de la mente", con independencia de que la comprensión consciente siga siendo considerada como una propiedad enigmática o misteriosa del cerebro y que el materialismo tenga sus propios límites. Los científicos, conscientes de las implicaciones metafísicas inherentes al campo de la neurociencia invitan a los filósofos a descubrir hechos nuevos aportados por los descubrimientos en el sistema nervioso. Algunos ni siquiera han esperado esta invitación. Patricia Churchland acuñó el término "neurofilosofía" para ofrecer una versión neurofilosófica del materialismo reduccionista y eliminativo. Searle y Dennett intentan crear vínculos entre filosofia, psiquiatría, psicología cognitiva, inteligencia artificial y neurociencias. Changeux ha animado a los filósofos a interesarse por las ciencias del cerebro. Eccles, junto con Penfield y Schrödinger, es uno de los raros neurocientíficos empeñados en defender todavía una tesis espiritualista en la forma de un dualismo interaccionista. En su obra The human mistery (1978), Eccles no se recata en decir que se trata de un ataque contra el materialismo monista, del que dice que constituye el credo de la ciencia oficial. Para Eccles, a la interacción no se la puede confundir con la teoría de la identidad, puesto que existe autonomía e independencia de lo mental (M2), e incluso desvincula al "yo" de cualquier perspectiva evolutiva, reservando únicamente la evolución al cerebro. Si a nivel ontogenético Eccles reconoce la pertinencia de la tesis de la emergencia de la conciencia de sí en la construcción del cerebro y de sus relaciones con el mundo exterior, la unidad vivida del yo no proviene de la com- 


\section{La naturalización de la mente}

plementariedad hemisférica del cerebro. Más adelante volveremos a referirnos a Eccles y a su teoría de los tres mundos cuando comentemos la posición de Penrose al respecto.

Mientras tanto, conviene subrayar que como la perspectiva materialista parece representar en la ciencia contemporánea una vía privilegiada, la filosofía de la mente deberá abandonar su estatuto tradicional de disciplina puramente especulativa o a priori, y tomar en consideración los datos procedentes de las neurociencias y de otras ciencias cognitivas, ya que la meta de toda ciencia natural es explicar los fenómenos en el nivel más elemental posible (la física, en el plano subatómico; la biología, en el plano genético y molecular; las neurociencias deberán encaminarse cada vez más hacia las células nerviosas y fenómenos químicos y eléctricos).

Aunque los neurocientíficos se sienten seguros porque se apoyan en ciencias con éxito, como la física y la biología, que posibilitan verificar si se avanza o no en las soluciones, sin embargo, estamos ante una disciplina joven que todavía tiene que definir sus interrogantes fundamentales, pero que en cuanto se practiquen los estudios neurocientíficos adecuados, todo lo referente al pensamiento y a los esquemas mentales irá adquiriendo una nueva dimensión. El reduccionismo neurocientífico es considerado el modelo explicativo actual más compatible con las exigencias de la ciencia. Lo que tal vez no sea cierto es que las neurociencias, tal como entendemos hoy el concepto de ciencia, representen la única disciplina a tener en cuenta en el estudio de los fenómenos mentales, ni que vayan a tener la última palabra en la explicación de los fenómenos de la mente ${ }^{15}$.

Por otro lado, reduccionismo no es lo mismo que dependencia, pero tampoco se identifica ni con el eliminativismo ni con el emergentismo. El que los fenómenos mentales dependan de sus correspondientes neuronales, no significa que los primeros se reduzcan a los segundos. Además, la reducción admite procesos psicológicos, contrariamente al primitivo materialismo eliminativo para el que lo mental no existe, de modo que cuando la ciencia progrese se cree que podremos estar en disposición de describir algo que existe en términos de ciencia física. Por eso, los eliminativistas acusan a los reduccionistas que defienden la teoría de la identidad, de "dualistas", la misma acusación, aunque más crítica, que hacen al emergentismo de Bunge, al que califican de reduccionismo moderado.

Así pues, el materialismo eliminativo fue más lejos que el materialismo reductivo. En general, los reduccionistas consideran que lo importante es esforzarse por integrar la teoría psicológica con la neu- 
robiológica, pero sin que esto suponga que los fenómenos reducidos desaparezcan o sean desacreditados. El materialismo eliminativo fue al principio más allá, al afirmar, como decía P.M. Churchland, que los fenómenos psicológicos constituían una teoría radicalmente falsa y tan defectuosa que tanto los principios que la regían como la ontología de esta teoría sería eventualmente desplazada, más bien que reducida, por la neurociencia ${ }^{16}$.

\subsection{Localismo/Asociacionismo}

$\mathrm{Al}$ comienzo, el reduccionismo estuvo íntimamente unido al localizacionismo, de modo que si triunfaba el localizacionismo, el reduccionismo había triunfado. Frente al reduccionismo localista que sostenía que la mente del hombre era idéntida a la actividad físico-química del cerebro, los holistas creían que la mente era una propiedad biológica que las leyes físico-químicas no podían explicar. K. Lashley, que trató de descubrir mediante lesiones producidas en áreas cerebrales específicas, el sustrato neural de determinadas conductas, llegó a poner en tela de juicio la localización e, incluso, el reduccionismo, es decir, el intento de explicar la conducta en función de principios neurales específicos, prescindiendo del plano psicológico o mentalista. Más bien, a partir de los conceptos de equipotencialidad (ley de acción masiva) y de plasticidad, habló de un cerebro global, o del cerebro como una totalidad. Aunque nunca demandó explicaciones mentalistas, porque siguio siendo discípulo de Watson, sí habló de "planes" y "estructuras" y allanó el camino a explicaciones mentalistas como las de Simon, Piaget, Müller, Chomsky, poniendo los fundamentos para un enfoque del pensamiento y de la conducta próximo a la ciencia cognitiva. En la misma línea se expresaron Flourens y Pribram, para quienes, en contra de las tesis dominantes en el campo neurocientífico y neuroanatómico, el sistema nervioso no es un mero conjunto de modalidades específicas de procesamiento, sino que las funciones cerebrales actúan como una totalidad, de modo que existe la posibilidad de que formas de conocimiento estén ampliamente difundidas a lo largo y ancho del cerebro. Así pues, el reduccionismo ya no está sólo en relación con el localizacionismo, sino que afecta también a la neurociencia, que irá de las regiones del sistema nervioso o hemisferios, a las células o localizaciones específicas, pudiendo afectar, por tanto, el reduccionismo a sistemas neurales más molares. Podemos decir que del reduccionismo localista se ha pasado a un reduccionismo, primero asociacionista, según 
el cual, el cerebro aparece como un conjunto de centros unidos entre sí y, más recientemente, al paralelismo, que resulta ser una concepción mucho más compleja del funcionamiento del cerebro: ahora, el cortex cerebral es concebido como un mosaico de áreas funcionalmente especializadas y unidas por conexiones paralelas.

Ya Hebb había terciado en la polémica localismo /asociacionismo y conexionismo tratando de ofrecer una síntesis, según la cual las pautas de conducta se van conformando a lo largo de períodos prolongados mediante la conexión de conjuntos particulares de células que él denominó "congregaciones" (assemblies); de modo que los comportamientos más complejos, o "secuencias de fases", están menos localizados y abarcan grupos mayores de células, que proceden de diversas áreas del sistema nervioso. Cuando el organismo madura es capaz de expresar conductas complejas, que resulta difícil atribuir a una serie aislada de neuronas de una región concreta.

Sin embargo, la cuestión central es si conceptos básicos como creencia, percepción, sensación, deseo, etc. pueden ser reemplazados por términos neurofisiológicos. P.S. Churchland se queja de que, desde posturas muy distintas como las dualistas, y menos comprensibles, como las de algunos físicos, no se considere que el estudio directo del cerebro sirva para lograr una teoría de cómo la mente/cerebro actúa. Este escepticismo procede tanto del convencimiento de que desde la neurociencia nunca se podrán explicar ni comprender cosas tales como la percepción, la memoria, la conciencia, la creencia, el deseo, etc. como de que, dado el alto grado de complejidad del sisterna nervioso, la aportación positiva del conocimiento cerebral podría ayudar a largo plazo, pero que no es previsible que sirva de ayuda en un futuro próximo ${ }^{17}$.

Patricia Churchland está convencida también y participa de la idea de que la explicación de los procesos neurocognitivos no puede lograrse desde los niveles más bajos de la organización del sistema nervioso, (tal como las sinapsis y las neuronas individuales), sino desde un nivel sistémico, en el que se apreciará el papel interactivo de los estados neuronales en la economía neurocognitiva. Edelman, en el marco de su teoría de la selección de grupos neuronales, afirma que las áreas del cerebro, que aparecen en el curso de la evolución, se coordinan para dar nacimiento a nuevas funciones. Edelman privilegia más que a la célula nerviosa, como unidad de selección, al grupo neuronal, al que otorga el poder de formar un sistema de funciones superiores del cerebro: memoria, categorización, aprendizaje, etc... Aunque tanto T.J. Sejnowski como P.S. Churchland ${ }^{18}$ dan buenas razones y tratan de 
justificar la necesidad de integración entre los niveles biológico y cognitivo, ellas mismas acaban proponiendo, como otros tantos, la necesidad de una ciencia integrada y unificada de la mente/cerebro en la que se combinen las exigencias de la neurobiología, de la psicología, de la neurofisiología, de la lingüística, de los modelos del computador, a pesar de que califican este objetivo como un sueño ${ }^{19}$. En la misma dirección, P.M. Churchland se inclina por una investigación interdisciplinar en la que "campos tales como la inteligencia artificial conexionista y la neurobiología computacional serán fuente de nuevas y mejores ideas sobre estas cuestiones» ${ }^{20}$. Como dice H. Gardner ${ }^{21}$, a la neurociencia hay que ubicarla en las fronteras de la ciencia cognitiva.

El desafio cognitivo exige una colaboración interdisciplinar indispensable, pudiendo establecer un diálogo entre filósofos y neurocientíficos en múltiples campos. Sin abandonar el terreno de la ciencia natural, parece obligado, como dice Dretske ${ }^{22}$, ser un realista sobre la mente y constatar que tenemos pensamientos, deseos, creencias, etc. y, al mismo tiempo, poder proclamarse materialista y afirmar que "los estados mentales son simplemente estados físicos del organismo". Si todavía no existe una teoría biológica, física o computacional que esté cerca de explicar nuestra comprensión consciente, eso no debería detenernos, como dice Penrose ${ }^{23}$, en nuestro intento de buscar una. No cabe duda de que el aspecto interior de la vida mental (eso que tradicionalmente llamamos "subjetividad»), constituye aún hoy «el punto ciego del naturalismo científico" ${ }^{24}$.

\subsection{Reduccionismo, conciencia y plasticidad del cerebro}

A este respecto, Nagel considera que ninguna teoría reduccionista será capaz de dar cuenta de lo más característico de los fenómenos mentales: la experiencia consciente. A pesar de ello, no quiere que se le acuse de dualista y, por eso, defiende, aun sin llegar a nombrarla, la teoría del doble aspecto, para la cual la mente constituiría la cara subjetiva y el cerebro la cara objetiva de una misma entidad. Missa llama a esta entidad mente/cerebro, y cree que la teoría del doble aspecto es la más idónea para servir de marco metafísico general para la investigación de los fenómenos de la mente/cerebro ${ }^{25}$. Estamos, en realidad, ante un dualismo de propiedades y no de substancias o cosas. Por ser, tanto el pensamiento como la extensión, propiedades, pueden pertenecer a la misma cosa, ya que una misma cosa puede tener propiedades diferentes. Lo que es un estado de conciencia desde el punto 
de vista de la autopercepción interna, es un proceso en el sistema nervioso o movimiento en el organismo desde el punto de vista de la percepción sensorial. Para esta teoría, lo mental y lo físico son fenómenos reales y resultaría arbitrario, filosóficamente hablando, decir que uno de ellos es prioritario. La teoría del doble aspecto, así como el materialismo, serían insostenibles si se mostrara que existen fenómenos mentales que no tienen correlatos físicos, cosa imposible de defender para la teoría de la identidad y para el materialismo eliminativo.

Volviendo al principio, debemos reconocer que si la mente tiene un lugar genuino en la naturaleza, y no cabe duda que lo tiene, entonces debe existir un lugar para su explicación. Si la neurociencia estudia el cerebro como un órgano del cuerpo, como un pedazo de materia que tiene una variedad de propiedades (eléctricas o químicas) intrínsecas $\mathrm{y}$, por supuesto, diversas relaciones con otros órganos internos, la psicología lo estudia como un consumidor de información sobre el entorno, como un trozo de materia que tiene relaciones extrínsecas con un entorno en el que tiene que tener lugar la acción. Disponemos de un objeto físico (el cerebro) con un conjunto de propiedades y, así, en términos parecidos a los de la teoría del doble aspecto, Dretske dirá que las propiedades intrínsecas (estudiadas por los neurobiólogos) lo definen como un órgano físico de cierto tipo. Las extrínsecas, aquellas que describimos cuando hablamos de lo que el organismo cree y conoce, de lo que ve y recuerda, son las relaciones que este órgano físico inicia con el resto del universo, la manera como este objeto externo representa el resto del mundo.

El cerebro es, pues, un artilugio representacional y el hecho de que el cerebro represente condiciones en el entorno del animal ayuda a explicar algo sobre la manera cómo el animal opera en este entorno. No es necesario acudir a nada fuera de lo viviente para justificar la vida y la conciencia. La propiedad fundamental del viviente es renovar sin cesar su interacción dinámica con el mundo, cuyo resultado produce bucles reflexivos, entre los cuales se encuentra la conciencia. La inevitable referencia del cerebro al entorno para su construcción obliga a considerar que no son los genes los que definen la condición del desarrollo de la especie humana, sino la epigénesis, con lo cual las diferencias culturales son otros tantos medios para que el potencial genético se actualice diferenciándose. Genésis y epigénesis configuran el marco dentro del cual es posible encontrar alguna explicación al desarrollo del sistema nervioso, estructural y funcionalmente, y es posible hacerlo en la medida en que la construcción del cerebro es vista como una continuidad dinámica entre el sistema nervioso del individuo 
y su entorno. Como dicen T.J. Sejnowski y P.S. Churchland ${ }^{26}$, «el cerebro tiene una notable habilidad para adaptarse a los cambios en el entorno a muchos niveles estructurales diferentes y en un rango amplio de escalas temporales". Pero en el origen, la especie humana y la totalidad de sus rasgos son el resultado físico de un proceso puramente físico. Por eso, se cree que la única diferencia entre distintos sistemas nerviosos es de grado, no de tipo. Si esto es así, no existe ninguna necesidad de postular la existencia de substancias no físicas para explicar lo que ocurre en nosotros. Si es verdad, por otro lado, que todo es materia, este dominio debe admitir la complejidad necesaria para dar cuenta de los diferentes grados de organización en el curso de la filogénesis y de la ontogénesis. El auténtico problema está, pues, en ver cómo rasgos distintivos de lo mental (intencionalidad, conciencia, subjetividad, etc) pueden tener lugar en una visión naturalista que ve las mentes como un producto de la evolución biológica y como poseedores de un substrato físico-químico, al igual que otros fenómenos biológicos ${ }^{27}$.

Sin salirnos de este contexto naturalista y evolucionista es posible integrar en él aspectos que son también definitorios del desarrollo cerebral, como son los factores del entorno, en especial los ideológicos, lingüísticos y culturales. El hecho de que la naturaleza humana no sea estable y que esté sometida al devenir del tiempo, no tiene por qué impedir una explicación reductiva o naturalista. La materia viviente está constituida por el tiempo, o mejor, como dice Andrieu ${ }^{28}$, "su espacio individualizado en el cuerpo humano es del tiempo incorporado y adaptado a las interacciones con el entorno cultural".

De este argumento no tiene porqué deducirse una conclusión antinaturalista y antireduccionista, como quieren algunos, en una dirección cercana al emergentismo, ya que, aun partiendo de la unidad material fundamental, como es el gen, irían surgiendo formas nuevas, con un estatuto específico y con una autonomía relativa, pero suficiente, como es el caso de la mente o de la conciencia, o de cualquier otro estado mental en relación con el cerebro. Querrían, en definitiva, preservar la existencia psicológica del estado mental como algo autónomo. Ser neurofilósofo no les parecería la solución para resolver los problemas que la neurociencia tiene planteados con la filosofia, porque sobre el material genético y su evolución emergen organizaciones nuevas con autonomía propia suficiente. Podríamos calificar estas posiciones, como hace P.M. Churchland con la de Searle, de híbridas ${ }^{29}$. En efecto, en la obra The Rediscovery of the Mind, Searle defiende y articula este punto de vista híbrido, porque, por un lado, afirma que las sensaciones, 


\section{La naturalización de la mente}

los pensamientos, y los fenómenos mentales en general, son todos estados o rasgos del cerebro, de modo que éste es la sede de toda actividad mental y, por otro, argumenta que todos los estados y actividades mentales no son ellos mismos estados físicos del cerebro. Ni son idénticos ni reducibles, sino metafísicamente distintos de los complicados estados físicos del cerebro.

Para Searle, los estados mentales forman una clase nueva y distinta de fenómenos, con sus propias peculiaridades (tales como el significado y la intencionalidad) y con sus modos peculiares de conducta (como ocurre, por ejemplo, en el razonamiento y la deliberación). A su juicio, sería en vano tratar de reducirlos a fenómenos meramente físicos. Existe entre ellos una relación causal recíproca. Para Searle, el principal objetivo de una teoría científica sobre la mente sería llegar a comprender la naturaleza particular de los fenómenos mentales, en especial rasgos como el de "significado" y, en segundo lugar, cómo estos rasgos no físicos del cerebro interactúan causalmente con sus rasgos puramente físicos.

P.M. Churchland califica esta posición de "conservadora moderna" ${ }^{30}$, conservadora porque defiende la realidad independiente y el status metafísico diferente de los estados mentales, y moderna, porque los sitúa como rasgos (no físicos) del cerebro y objetos propios de estudio científico y, en su conjunto, la considera una posición inestable o variable. Para P.M. Churchland, lo que Searle descubre no es la mente misma, sino únicamente nuestra concepción precientífica y de sentido común de la mente. Por contra, el objetivo de la ciencia es descubrir una concepción nueva y más profunda de los fenómenos mentales, aceptando como algo irrenunciable su plasticidad y el hecho de que la conciencia está determinada por el entorno cultural, principalmente ideológico, lingüístico y práctico, sin que esto suponga prescindir de una explicación naturalística e incluso reduccionista. El modelo al que acude es el conexionista, de acuerdo con el cual el aparato cognitivo básico de cada uno consta de una amplia red de unidades interconectadas, que admiten variaciones en los pesos de sus conexiones. Cada neurona es capaz de recibir conexiones sinápticas de alrededor de otras tres mil neuronas. Un cerebro humano puede contener del orden de 10 (14) conexiones sinápticas y de 10 (10) (14) configuraciones cognitivas distintas. De aquí concluye Churchland que los reduccionistas no necesitan negar el carácter plástico de la conducta humana. Por el contrario, están en una posición excelente para poderla explicar con algún detalle ${ }^{31}$.

El cerebro dispone de cien mil millones de unidades neuronales de procesamiento, cuyo funcionamiento cooperativo y en paralelo permite 
llevar a cabo sus actividades. El modelo conexionista, rechazado por Penrose, está inspirado en nuestra comprensión del cerebro, aunque no ofrezca una explicación detallada de los procesos neurales. La pretensión de P.M. Churchland de ofrecer una visión naturalista e incluso reduccionista se concreta en una aproximación llamada conexionismo que estaría en el punto de unión de la neurociencia computacional, de la psicología cognitiva y de la inteligencia artificial ${ }^{32}$.

El modelo conexionista es congruente con los sistemas de procesamiento en paralelo distribuido, según los cuales las funciones de entrada y salida están ejecutadas por configuraciones llamadas "redes", que constan de muchas unidades que admiten diversos niveles de activación, y de muchas conexiones de activación-transformación entre estas unidades, con fuerzas estables, pero modificables. Lo que está queriendo decir P.M. Churchland es que la plasticidad de la conciencia es real, pero que no va más allá de una explicación naturalista, ni siquiera cuando se consideran las categorías de nuestra cultura como acontecimientos importantes para la conformación del funcionamiento cerebral. De esas categorías puede darse también una explicación naturalista, puesto que la articulación del cerebro depende de la naturaleza del hombre y de su esencia cultural.

\subsection{Los Churchlands y el materialismo eliminativo: precisiones}

Los Churchlands confiesan que ha sido necesario argumentar en favor de la relevancia de la neurociencia porque muchos psicólogos, principalmente Fodor y Pylyshyn, han pretendido explicar amplia y extensamente porqué la neurociencia era irrelevante, y porqué la neurofilosofia, en la lingüística y en algunas áreas de la psicología, era un hecho. No obstante, los propios Churchlands, después de decir que muchos psicólogos están de acuerdo en que la psicología científica va a producir cambios importantes respecto a las viejas formas de pensar sobre la mente y sobre los procesos mentales, reconocen que la "coevolución de la microteoría y de la macroteoría, es decir, de la neurociencia y de la psicología, es un tema metodológico mayor de principio a fin ${ }^{33}$. Los Churchlands, adoptando un lenguaje más suave y matizado, no pretenden "eliminar" la conciencia. Su materialismo eliminativo viene a decir esencialmente ahora que, como las ciencias avanzan, "algunas categorías naturales que figuran en la primitiva teoría no tienen porqué tener un papel en la nueva teoría (que la reemplaza), la cual es considerada con capacidad para proporcionar una explicación 
correcta de un cierto rango de fenómenos". Un cambio de teoría no conlleva ipso facto una modificación de la naturaleza del mundo. Lo que se ha modificado ha sido sólo nuestra comprensión del mundo. $\mathrm{Y}$ literalmente dice que «alguien que piense que el materialismo eliminativo significa que alguna parte de las cosas en sí (por ejemplo, los qualia o las actitudes proposicionales) es eliminada por una simple modificación de la teoría, está confundido» ${ }^{34}$.

El materialismo eliminativo no elimina nada de lo que existe. $\mathrm{Si}$ existe el espíritu vital, ningún teórico puede hacerlo desaparecer. Lo que los Churchlands quieren dejar claro es que «la biología molecular puede explicar los fenómenos biológicos perfectamente bien sin apelar al espíritu vital" ${ }^{35}$. Están de acuerdo en que, tal vez, hubiera sido preferible haber utilizado otra expresión distinta de la de «materialismo eliminativo" para evitar falsas interpretaciones. Pero eso no autoriza, a su juicio, el que se puedan mantener argumentos como el de Nagel, tal como los expone en su ya clásico artículo What is it like to be a bat?, en el que concluye que de los fenómenos conscientes no se puede dar una explicación puramente física: una ciencia puramente física parece tener algunos límites, límites que se extienden al carácter subjetivo de los contenidos de conciencia. Para P.M. Churchland, el argumento de Nagel es tomado como una bandera en torno a la cual se mueve cualquier opinión antireductiva. ¿Es esto una demostración de que existe un aspecto no físico en los estados conscientes a los que cada uno tendría acceso directo y privilegiado y los otros sólo podrían inferirlos? Para P.M. Churchland, no está claro. En cualquier caso, el mismo acceso tenemos cada cual a la configuración física de nuestro propio cuerpo $\mathrm{y}$ de sus miembros ${ }^{36}$, porque únicamente el cerebro de cada uno disfruta de las conexiones causales relevantes para su cuerpo, y las demás deben utilizar otros medios para conocer nuestra configuración corporal: deben verla, o sentirla con sus manos, o fotografiarla, etc. Por tanto, también en lo referente a los aspectos corporales existe la misma divergencia que con relación a los propios estados mentales. El acceso epistemológico de primera persona a algunos fenómenos no significa que el fenómeno accedido sea de naturaleza no física. Simplemente que alguien posee alguna conexión causal de inferencia a este fenómeno que los demás no tienen. Dice P.M. Churchland que «la diferencia entre mi conocimiento del sonrojo facial y tu conocimiento de mi sonrojo facial está, no en la cara conocida, sino en la manera de conocerla: yo la conozco por un medio autoconectado (mi sistema somato-sensorial), mientras tú la conoces por un medio heteroconectado (tu sistema visual) ${ }^{37}$. 
La simple existencia de formas epistémicas autoconectadas no requiere la existencia de rasgos no físicos. P.M. Churchland dirá que si existen, habrá que razonarlos y argumentarlos de otra manera. En el fondo del razonamiento de Churchland se encuentra una concepción de la ciencia que tiene en cuenta no sólo el contexto de justificación, sino también los procesos de descubrimiento y según la cual teorías dominantes en un momento de la historia de una ciencia han sido sustituidas por otras a las que se concede una mayor capacidad explicativa. Resulta paradigmática al respecto la teoria del flogisto, del fluido calórico y del éter huminífero para la teoría eliminativista, puesto que las teorías en las que dichas entidades se invocaban fueron reemplazadas por otras en las que esas entidades ya no jugaban ningún papel. La comunidad científica llegó a reconocer poco a poco que el flogisto y el resto de entidades no existían. Pueden servir de ejemplos acerca de lo que pretenden argumentos eliminativistas, a saber, que la teoría en la que se convocan ciertas entidades o procesos, serán rechazadas y reemplazadas por una teoría mejor. Pero una cosa es rechazar o reemplazar una teoría, incluso decir que es errónea, y otra decir que las entidades sobre las que esas teorías versan no existen. $\mathrm{Al}$ igual que ni Copérnico ni Galileo llegaron a afirmar que los planetas de los que hablaba Ptolomeo no existían, tampoco se puede llegar a decir que las entidades sobre las que versan las teorías del sentido común (en las que las actitudes proposicionales encuentran su asiento) y que son reemplazadas por una teoría mejor, no existan.

Según P.M. Churchland, cuando, en general, una teoría de nivel más profundo o general es capaz de subsumir el retrato completo de la realidad encarnada en alguna teoría o en algún marco conceptual más primitivo, decimos que el marco primitivo ha sido reducido por el nuevo marco y la teoría más general. Decimos entonces que los fenómenos del marco primitivo han resultado ser casos especiales de los fenómenos descritos en la teoría nueva y más profunda ${ }^{38}$. Esto es lo que sucede, a juicio de Churchland, con los fenómenos mentales, en general, y con el fenómeno de la conciencia, en particular. Todos ellos son fenómenos cerebrales y la conciencia, en concreto, es un fenómeno mental importante y real, que la neurociencia debe reconocer como un objetivo prioritario de su interés explicativo.

Por eso, concluye diciendo que «la naturaleza inaccesible de los fenómenos conscientes está claramente escrita en el alfabeto de la actividad neuronal que tiene lugar dentro del propio cerebro y del sistema nervioso. Además, uno tiene acceso contínuo a amplias zonas de esa actividad aquí y ahora, por medio de caminos autoconectados 


\section{La naturalización de la mente}

del propio cerebro, y en virtud de la capacidad del cerebro para la autorrepresentación" ${ }^{39}$. Por tanto, los qualia y las actitudes proposicionales existen, pero la comprensión que tenemos de las mismas no responde, según los Churchlands, a los viejos esquemas de la folkpsychology. No hace falta ser un eliminativista para sostener que las propiedades experienciales son propiedades físicas. Basta adoptar una postura naturalista en virtud de la cual poder explicar que los organismos son conscientes por alguna propiedad natural del cerebro ${ }^{40}$.

La actividad mental es un fenómeno natural y, como tal, debe encontrar su explicación dentro del ámbito físico, aunque, como hemos recordado al principio, esto implique ampliar los marcos en los que se mueve actualmente la investigación científica en el campo de la física.

Todos constatamos que los estados cerebrales causan estados conscientes y que este nexo causal debe hacerse a través de conexiones necesarias de algún tipo que hagan posible la comprensión de ese nexo. Al igual que la vida, de la que nadie discute en estos momentos que procedió por evolución de la materia inorgánica, y no por alguna forma de emergencia milagrosa, tampoco la conciencia, como hecho natural que es, vinculado precisamente al fenómeno de la vida. Que la conozcamos o no, debe haber alguna explicación natural de la vida a partir de su origen material $\mathrm{y}$, por tanto, de la conciencia, como desarrollo biológico ulterior. Pretender apartar un hecho natural de una explicación natural es un prejuicio epistemológico racionalmente injustificable. Por eso, carece de justificación racional pensar, como hacen los analistas, que lo mental inhiere en una especial substancia no física, la mente, a veces llamada alma o espíritu.

La mente, para el dualista, es el alma en la máquina y la considera un tipo especial de materia o entidad, de cuya naturaleza nada tiene que decir la neurociencia. En consecuencia, la psicología no puede reducirse nunca a la neurociencia. Había que preservar para la psicología un campo de autonomía propio, haciendo así difícil, si no imposible, la integración de los niveles biológico y cognitivo. Strawson se refiere a aquellos que, utilizando un lenguaje más suave, hablan de asimetría entre lo mental y lo físico, en particular entre los fenómenos experienciales y no experienciales ${ }^{41}$, dado que, así como parece natural que cuando exista una realidad experiencial existe una realidad no experiencial, no es correcto afirmar que lo no experiencial dependa de lo experiencial, porque puede existir una realidad no experiencial sin experiencia. Pero eso no puede ser nunca un argumento contra la irreductibilidad, porque, en realidad, como señala Strawson, «la apariencia de irreductibilidad es una ilusión generada por la ignorancia humana» ${ }^{42}$. 
En efecto, el desconocimiento de la física del cerebro es un hecho natural con el que hay que contar, pero que lo único que debe provocar es un esfuerzo más exigente para buscar correlaciones entre las variaciones de los fenómenos experienciales. $\mathrm{O}$, como señala Warner ${ }^{43}$, "nadie ha ofrecido una descripción mínimamente plausible de un sistema de pensamiento no físicon. La introspección y la aceptación del acceso privilegiado e incorregible a los fenómenos de primera persona no es capaz de ofrecer una explicación inteligible de los estados conscientes como dependientes del cerebro. Y, sin embargo, no debe existir, según McGinn ${ }^{44}$, una dificultad metafísica 0 conceptual intrínseca acerca de cómo la conciencia depende del cerebro. Resulta indudable a estas alturas que la capacidad cognitiva humana es un sistema modular biologicamente basado, aunque existen problemas que escapan sistemáticamente a los mejores esfuerzos teoréticos, como es el caso de la comprensión consciente, lo cual no hace nada más que apuntar que la filosofía confirma la biología.

En ningún caso debe esto llevar a la conclusión de filósofos que, como Nagel y Searle, insisten en que la atención que prestan al reino subjetivo es lo que se necesita si la filosofía no quiere caer en el dogmatismo. Uno y otro consideran que es la conciencia la que hace el problema mente/cerebro intratable. Como nos recuerda Rorty ${ }^{45}$, los oponentes a ambos autores califican sus teorías de obscurantismo pregalileano, a pesar de que siempre se ha tropezado con la dificultad que ha supuesto estudiar el sistema nervioso, dificultad paliada en los últimos tiempos, puesto que se dispone de nuevas técnicas para investigar las funciones del cerebro, que hacen posible una descripción estructural y funcional mucho más detallada. Estos desarrollos sugieren, a juicio de Sejnowski y P.S. Churchland ${ }^{46}$, que ahora es posible comenzar por integrar niveles y por construir teorías que expliquen las propiedades funcionales del tejido neural. En el fondo resultaría muy cómodo si pudiéramos llegar a comprender la naturaleza del cerebro. Pero, a su juicio, resulta muy difícil, por no decir imposible, teorizar sobre estas cuestiones en ausencia de exigencias neurobiológicas. "La neurobiología es indispensable para el descubrimiento de teorías que expliquen cómo ejecutamos tareas tales como ver, pensar y conocer» ${ }^{47}$.

\subsection{La actividad mental: carácter configuracional}

Podríamos hacer una analogía respecto a la cognición con aquello que Galileo decía refiriéndose a la naturaleza en general, a saber, que era un libro abierto, que, para saberlo leer, era preciso conocer 


\section{La naturalización de la mente}

el lenguaje en el que estaba escrito. Ese lenguaje era el de las matemáticas. Pues bien, la cognición será un libro abierto una vez que lleguemos a comprender los detalles de todas y cada una de las neuronas y de su desarrollo, conectividad, propiedades de respuesta, etc. El objetivo deseable es, pues, según Sejnowski y P.S. Churchland, la integración reductiva de las ciencias psicológicas y neurobiológicas, dado el carácter interdisciplinar de la neurociencia cognitiva. Haciéndose eco de una tesis que P.S. Churchland había mantenido en 1986, afirman que «una reducción integrativa entre teorías a diferentes niveles puede proporcionar intuiciones que enriquecen los principios a ambos niveles" ${ }^{48}$.

Se hace necesaria una convergencia en la investigación de campos que, como la neurociencia, la ciencia cognitiva y la teoría computacional, hasta no hace mucho caminaban por separado, porque se están produciendo progresos en las teorías neurobiológicas y psicológicas desde los cuales se explica cómo las redes de neuronas logran efectos de alto nivel. Pueden existir especies en las que los estados particulares sean idénticos y reducibles a configuraciones neurales específicas, pero en la especie humana los fenómenos cognitivos de alto nivel no se pueden lograr al nivel más bajo de organización del sistema nervioso, tal como sinapsis o neuronas individuales, sino a niveles estructurales más altos, tales como sistemas o redes. El sistema nervioso está estructurado arquitectónicamente por niveles, en cuya formación y organización han intervenido múltiples factores de conexión con la información proveniente del medio, que ha ido modelando los sistemas de redes interconectadas en función de las necesidades cada vez más complejas de adaptación de todo organismo humano a las exigencias del entorno, desde los comportamientos más elementales y de más bajo nivel, hasta los comportamientos de más alto nivel cognitivo para cuya manifestación ha sido necesario desarrollar estructuras arquitectónicas neurales de funcionamiento complejo. Como dice Rumelhart ${ }^{49}$, «el cerebro despliega muchos elementos de procesamiento cooperativamente y en paralelo para llevar a cabo sus actividades". Así pues, ninguna conducta, y mucho menos las conductas más complejas, son producto de un componente singular y separado del sistema cognitivo, sino el producto de un conjunto amplio de componentes interactuantes, que se exigen mutuamente y que contribuyen cada uno a su manera a la conducta globalmente observable del sistema. La organización y configuración arquitectónica del sistema nervioso es la que permite patrones de conducta altamente complejos y estructurados, dado que la estructura conductual no emerge mágicamente 
del caos neural ${ }^{50}$. Toda conducta y, a fortiori las más complejas (como el pensar sobre el pensamiento), requieren una planificación tal a nivel cerebral que se convierta en el texto donde poder leer todo el conocimiento del que uno dispone. Como dice Young, refiriéndose al cerebro, "debemos tener in mente la evidencia de que este órgano contiene de alguna forma la base de la vida consciente de cada uno, el registro de todos nuestros objetivos, ambiciones, y es esencial para la experiencia de todos los placeres y dolores, todos los amores y aversiones ${ }^{51}$.

\subsection{Neurociencia y psicología del sentido común. La ambigüedad de Penrose}

Así pues, el cerebro contendría toda nuestra capacidad para la vida consciente. De hecho, la mayoría de neurocientíficos, neurofisiólogos y neuropsicólogos no se preocupan de la relación mente/cerebro. Entienden que una vez en el camino de descifrar los códigos que nos permitan leer con sentido el texto cerebral, la mayoría de dificultades y problemas se reducen a mera cuestión semántica. Sin embargo, sigue siendo cierto que el sistema de representación utilizado por el cerebro es todavía hoy menos comprensible que el sistema de representación más poderoso que conocemos, como es el lenguaje, el cual, a su vez, depende de nuestra explicación de cómo el cerebro es capaz de representar el mundo. Como dice P.S. Churchland, "no hay razón, en este estadio de la investigación, para creer que la representación típica de la conducta lingüística constituirá un caso único e inexplicable de representación" ${ }^{52}$.

La mentalidad no es separable del cerebro ${ }^{53}$. Los poderes intelectuales y emocionales requieren actividad en el cerebro y somos completamente dependientes de ella. Toda actividad mental, desde la más simple a la más compleja, está acompañada de eventos en el cerebro. La mente no es una cosa. Convendría decir mejor que la conciencia y la mentalidad son propiedades características que acompañan ciertas actividades del cerebro. Tal vez ni siquiera es correcto afirmar que los eventos cerebrales causen las actividades mentales ${ }^{54}$. Sería mejor decir que los acontecimientos mentales están asociados con cambios en el cerebro o que toda actividad mental está acompañada por la acción en el cerebro. No obstante, a pesar de situar la actividad mental ineludiblemente vinculada a la actividad cerebral, no resulta fácil poder establecer leyes de forma completa, puesto que, dada la complejidad 
y la adaptabilidad del cerebro, hacer una previsión precisa de las correlaciones entre los eventos mentales y los procesos físicos no es nunca posible. A pesar de todo, como dice P.S. Churchland, "seguramente es mejor estar guiado por los hechos empíricos sobre la actividad cerebral, tal como la neurociencia nos indica, que por la antigua y ruinosa teoría de la actividad cognitiva envuelta en el idioma intencional del sentido común" ${ }^{55}$.

Sin necesidad de establecer este corte o ruptura epistemológica y metodológica entre la neurociencia y la psicología del sentido común, los datos de los que actualmente disponemos avalan una orientacion neurocientífica en la explicación de los fenómenos mentales. El cerebro, además de un órgano físico, es también analizable desde el punto de vista de sus actividades, algunas de las cuales están íntimamente asociadas con los denominados eventos mentales. El cerebro no es un simple objeto visible y tangible, sino un sistema con una organización definida, con sus propiedades y acciones, una organizacion en parte heredada y en parte aprendida. No es sólo un almacén de recuerdos, sino un organizador activo, que inicia y dirige las acciones del resto del cuerpo, incluidas las actividades mentales. El cerebro humano, además de estar provisto por herencia de ciertos programas simples, contiene unos dispositivos que lo hacen capaz de poder aprender programas más elaborados. Por eso, Young habla en plural de "programas del cerebro", aunque sería mejor que fuésemos capaces de decir en algún lenguaje técnico cómo las células nerviosas actúan conjuntamente cuando pensamos, por ejemplo, sobre nuestros pensamientos o cuando seleccionamos nuestras acciones. Al no ser esto todavía posible, habrá que hacer un esfuerzo por identificar programas. "Los programas son conjuntos organizados de neuronas y sus conexiones, entre las cuales se hace la selección para producir estados y acciones mentales y cerebrales. Todo depende de las capacidades del cerebro, en parte heredadas y en parte aprendidas" ${ }^{56}$.

Los programas de la vida son, por ello, complicados, adaptables y creativos. Hasta los organismos más simples son sistemas inmensamente complejos, continuamente activos, que cambian de un momento a otro $\mathrm{y}$, por eso, se hace difícil ofrecer una visión consistente de cómo el sistema nervioso que utiliza programas tiene potencialidad para muchos tipos de acciones ${ }^{57}$. En el universo conncido, ningún sistema presenta el grado de complejidad de los seres vivos y, dentro de éstos, en el caso de la especie humana,la complejidad de su sistema nervioso, junto con los efectos que su actividad produce, han hecho decir que no es posible explicarlos acudiendo al modelo tradicional de 
ciencia natural, como dice Penrose, la actividad mental habría que situarla en un área de la física que está fuera de las leyes físicas actualmente conocidas ${ }^{58}$.

Además de la complejidad intrínseca de la estructura cerebral, tal como se observa desde una perspectiva evolucionaria, nuestra conducta está también gobernada, como dice P.M. Churchland, por lo aprendido en el pasado y por los planes de futuro, así como por nuestras percepciones conscientes. Esto permite que, aunque el desarrollo de la organización interna del cerebro está bajo el control del propio cerebro (lo cual no nos hace escapar del reino animal), seamos sus miembros más creativos e impredecibles ${ }^{59}$. De ahí que la tesis que Penrose mantiene es que la acción física del cerebro provoca conocimiento, aunque dicha acción física no puede ser simulada adecuadamente de forma computacional. A partir de aquí postula la necesidad de una teoría física nueva que mire más allá de lo que la ciencia conocida ofrece, si queremos encontrar alguna explicación del fenómeno de la conciencia, y expresa su satisfacción al ver cómo los físicos, que están más en contacto con los misterios de la materia, tienden a adoptar una visión del mundo menos mecanicista que la de los bi6logos ${ }^{60}$.

Según Penrose, ningún procedimiento algorítmico ejecutado por un programa standard de ordenador podría explicar la totalidad del conocimiento humano y la competencia en matemáticas. Penrose se apoya en el teorema de Gödel respecto a la incompletud de cualquier axiomatización de la aritmética para concluir, como otros muchos, que el conocimiento humano de las verdades matemáticas no puede ser completamente explicado en términos de nuestros procedimientos algorítmicos al uso. No obstante, en Las Sombras de la Mente, Penrose alude al fenómeno matemático reciente que lleva el nombre de caos, en el que los sistemas físicos parecen comportarse de manera incontrolada e impredecible y se pregunta si el fenómeno del caos proporciona la base física no computable necesaria para defender su punto de vista de que, aunque la acción física del cerebro provoca conocimiento, no puede ser simulada adecuadamente de forma computacional.

Pues bien, Penrose afirma literalmente (después de poner el ejemplo del juego de billar americano, que pretende entronerar la última bola de una cadena de zig-zag, y de decir que «ninguna computación podrá predecir el comportamiento real de las últimas bolas"), que, "a pesar de estas profundas dificultades para la predicción determinista, todos los sistemas normales que se conocen como "caóticos" deben incluirse dentro de lo que yo llamo computacionales» ${ }^{61}$. Para Penrose, la actividad mental consciente, de estar basada en alguna acción física, debe estarlo 
en una que no sea computable y, por tanto, los dispositivos capaces de realizar esas acciones podrían llegar a alcanzar inteligencia y conocimiento real; no obstante, califica esta especulación de extraordinariamente prematura ${ }^{62}$.

Aunque por diferentes razones, Penrose y P.M. Churchland están de acuerdo en afirmar que los distintos tipos de procedimientos algorítmicos llevados a cabo por un programa de ordenador standard explicaría la autonomía completa del conocimiento humano y la competencia en matemáticas. Penrose se apoya para ello en el teorema de Gödel, según el cual, ningún sistema formal válido de reglas de demostración matemática puede ser suficiente para establecer todas las proposiciones verdaderas de la aritmética ordinaria. Deben existir verdades aritméticas que se salen fuera del cualquier sistema algorítmico particular. Pero Penrose va más lejos y extrapola los resultados de este teorema a la intuición y comprensión humanas, de las que dice que "no pueden reducirse a ningún conjunto de reglas computacionales", para concluir, en base a esta interpretación del teorema, que «debe haber más en el pensamiento humano de lo que puede alcanzar nunca un ordenador en el sentido en que hoy entendemos el término ordenador" ${ }^{63}$.

Para P.M. Churchland ${ }^{64}$, lo que Penrose pretende es defender la hipótesis de que los seres humanos poseen una capacidad no algorítmica para el conocimiento de las verdades matemáticas y que disponen de una intuición que no depende del juego de un conjunto de reglas. Pero no está de acuerdo con Penrose en la localización que éste hace de esta capacidad no algorítmica y que sitúa en el dominio de la mecánica cuántica, porque, a su juicio, los procesos cuánticos, aunque son regularmente no algorítmicos, no parecen muy recomendables como computaciones reconocibles. Por otro lado, Churchland sostiene que no es necesario detenerse en el campo de la mecánica cuántica para encontrar un dominio abonado de procesos no algorítmicos. Ocurre ya en el ámbito de las redes neurales, para cuyo funcionamiento en paralelo no exigen estar sometidas a las instrucciones de un conjunto de reglas almacenadas. Mora, refiriéndose a las dos obras de Penrose, La nueva mente del emperador y Las sombras de la mente, califica, en el artículo citado, sus reflexiones, de obscuras y un tanto misteriosas acerca de un componente cuántico no algorítmico del funcionamiento cerebral y un componente neuronal, los microtúbulos.

La actitud de Penrose, a mi juicio, resulta, cuando menos, titubeante en este punto. Después de manifestar no estar de acuerdo con los que niegan que la mente se puede explicar en términos científicos, y 
de decir que las únicas mentes de las que tenemos conocimiento directo son las que están asociadas con objetos físicos concretos (los cerebros), afirma de una manera un tanto sutil y sospechosa lo siguiente: «incluso los estados mentales de consciencia, parecen estar asociados a ciertos tipos específicos de actividad física que tienen lugar dentro del cerebro", y añade, "si no fuera por los aspectos enigmáticos de la consciencia que están relacionados con la presencia de conocimiento y quizás con nuestras sensaciones de libre albedrío, que hasta ahora parecen eludir la descripción física, no tendríamos que sentirnos tentados a mirar más allá de los métodos standard de la ciencia para la explicación de las mentes como una característica del comportamiento físico de los cerebros" ${ }^{65}$.

Tal vez sin pretenderlo, reserva un halo de misterio para toda la dimensión de los fenómenos mentales, que le hace superar los métodos standard de la ciencia, aunque sin romper con ellos, obligándose a mantener una especie de equilibrio tensional entre las exigencias de la ciencia y los enigmas de la actividad mental que, a su juicio, parece eludir una explicación física, a pesar de que reafirma insistentemente el hecho de que el fenómeno de la conciencia sólo puede surgir en presencia de algún proceso físico no computacional que tiene lugar en el cerebro, al que considera dotado de una sutil y compleja organización que permite sacar provecho de la física no computable o medida cuántica, como prerequisito para una comprensión de la mente.

Digamos, pues, que, para Penrose, la mentalidad puede ser entendida en términos científicos, aunque no computacionales ${ }^{66}$, puesto que la comprensión no es una cualidad computacional, al igual que no lo son la capacidad para sentir la belleza y la capacidad para emitir juicios morales, cualidades todas ajenas en un ordenador actual. Aunque Penrose, a diferencia de Eccles, excluye cualquier explicación dualista del problema mente/cerebro, ambos coinciden, sin embargo, en acudir a la física cuántica para establecer una clara diferencia entre la actividad mental y la actividad cerebral. Penrose precisará, no obstante, que es necesario que los físicos cambien algunas de sus perspectivas para que añadan a su imagen actual del mundo físico el fenómeno de la conciencia. Eccles, por el contrario, respondiendo a la objeción materialista de que los eventos mentales inmateriales no pueden actuar sobre las estructuras materiales (como las neuronas de la corteza cerebral), afirma que es propia de aquellos físicos, neurocientíficos y filósofos que no han superado la física de la época y que no reconocen «la revolución forjada por los físicos cuánticos del 
s. XX" ${ }^{67}$. Si, para Eccles, la actividad mental presente en las intenciones o en el pensamiento puede llegar a causar eventos neurales mediante un proceso análogo a los campos de posibilidad de la mecánica cuántica, para Penrose, refiriéndose a la comprensión consciente y, en especial, a la comprensión matemática, afirma que "es esencialmente imposible que una cualidad semejante pueda haber surgido como una característica de la nueva acción computacional, ni pueda ser siquiera simulada adecuadamente por la computación». Y conluye diciendo que "cualquiera que sea la actividad cerebral responsable de la conciencia...., debe depender de una física que está más allá de la simulación computacional" ${ }^{68}$.

¿Cuál es, pues, la relación entre esta nueva física cerebral que Penrose propone y el fenómeno de la comprensión consciente que pretende explicar? Para responder a esta cuestión acude a un esquema parecido al de los tres mundos de Popper y Eccles, aunque matiza que «mi énfasis será muy diferente». Unos y otro admiten la existencia de tres mundos que aluden a tres ordenes de realidad diferentes: el mundo físico, el mundo de nuestras experiencias conscientes y el mundo del conocimiento en sentido objetivo, que Penrose circunscribe al mundo platónico de las experiencias matemáticas. Eccles proclama la autonomía tanto del mundo de la materia-energía, como del mundo mental, pero lo relevante es el modo de acción de los eventos mentales sobre los neurales $\mathrm{y}$, viceversa, a través de la frontera e interfase que separa los dos mundos por medio del cerebro de relación. La autonomía no supone independencia, sino interacción, aunque manteniendo el hecho dual de los dos mundos y produciéndose la interacción de forma «análoga al campo de posibilidad de la mecánica cuántica, que no posee ni masa ni energía, pero que puede causar una acción eficaz en microespacios» 69 .

Así pues, el mundo físico es un mundo abierto al flujo de información y no un mundo clausurado tal como, a su juicio, difienden las teorías materialistas de la mente. No obstante, el propio Eccles reconoce que la teoría dualista interaccionista entra en conflicto con las leyes naturales actuales y se asume que la actividad cerebral opera en permanente acuerdo con las leyes naturales, excepto en lo que respecta a su apertura a las influencias del mundo mental ${ }^{70}$. Lo que Eccles deja bien claro es que nos encontramos ante dos entidades completamente separadas que se comunican a través de los microespacios del cerebro, a pesar de lo cual, sigue considerando, como Popper, que el surgimiento de la conciencia completa es realmente uno de los milagros más grandes. Si no de milagro, sí de misterio califica Penrose 
las posibles relaciones que mantienen entre sí estos tres mundos. El no habla de interacción, sino de cómo, por un lado, el mundo matemático desempeña un papel tan importante en el comportamiento del mundo físico, hasta el punto de que el propio mundo físico parece emerger casi misteriosamente del mundo platónico de las matemáticas. Por otro, cómo es posible que seres con capacidad de percepción puedan surgir a partir del mundo físico, y, finalmente, cómo la mentalidad es capaz de crear conceptos matemáticos a partir de algún tipo de modelo mental. Penrose, fiel seguidor de la creencia platónica, concede prioridad al mundo de las formas perfectas, del que tanto el mundo mental como el mundo físico serían sus sombras ${ }^{71}$.

No obstante, adopta una posición dubitativa asumiendo la posibilidad de que existan aspectos de los tres mundos que no puedan ser explicados a partir del inmediatamente anterior y, en concreto, que haya "una vida mental que no está enraizada en estructuras físicas" ${ }^{72}$. Pero vuelve a reaccionar para achacar a nuestra falta de comprensión de la materia el que no sepamos aún qué tipo de organización existe en el mundo físico que da lugar a los seres conscientes, aventurando de nuevo la hipótesis de que, en cualquier caso, sólo desde la nueva concepción de la física, propia de la mecánica cuántica, nos podemos acercar al misterio para acomodar la mentalidad dentro del mundo de la realidad física, porque, según su punto de vista, dentro de la camisa de fuerza de la mecánica clásica "no puede haber ninguna función científica para la intencionalidad y la experiencia subjetiva" ${ }^{73}$.

Es evidente que existe todavía, para Eccles y Penrose, en terminología de Mora, un halo de misterio y no de problema, en todo lo referente a la vida mental, especialmente a la explicación de la conciencia, pero esto no autoriza, desde las exigencias mínimas de una metodología científica, a postular la existencia de procesos causales que escapen a nuestra comprensión científica. Si todo lo que la ciencia ignora tuviéramos que atribuirlo todavía a no se sabe qué causas extrañas, los avances científicos seguirían un retraso mayor. Por consiguiente, resulta imprescindible, en el marco de una orientación científica, aventuar nuevas hipótesis de trabajo que nos permitan acceder a un mejor conocimiento de los fenómenos mentales. Situarse en un mundo platónico para, desde él, dirimir acerca del ser y del conocimiento de lo que Penrose llama sus sombras (mundo físico y mundo mental) es una opción intelectualmente legítima. Lo que no está legitimado es hacer depender de él el ser, la esencia y el conocimiento de las llamadas "sombras", en un intento de prescindir de cualquier referencia a una explicación naturalista. 


\section{Conclusión}

Existen dos problemas que han dificultado y siguen dificultando el tratamiento científico de los problemas de la mente. Un problema intrínseco, derivado de la naturaleza misma del objeto de estudio, y un segundo problema, derivado de los intentos de lograr una ciencia unificada de la naturaleza, de modo que los problemas en filosofia de la mente se han encontrado a sí mismos sistemáticamente reconstruidos como problemas en la filosofia de la ciencia y, por tanto, exigen un lugar separado y autónomo para la folk-psychology. Otros, por el contrario, como W.V. Quine, los Churchlands, Cliff, Hooker, etc. conceden un alto valor a la unidad $\mathbf{y}$, por consiguiente, insisten en que no se puede proteger indefinidamente la psicología del sentido común. Por el contrario, debe ser reducida, por ejemplo, a una neurobiología cognitiva madura, quizás sufriendo alguna modificación en el proceso. Ha sido así como los problemas de filosofía de la mente se han ido reconstruyendo sistemáticamente como problemas en filosofía de la ciencia. Problemas que han sido centrales en las dicusiones filosóficas sobre la naturaleza de la mente, tales como las cualidades (qualia) sensoriales subjetivas y el problema de la representacion mental, hoy pueden darse de ellos una explicación mejor fundada desde los desarrollos recientes en la psicología fisiológica y en la neurobiología cognitiva ${ }^{74}$.

Es evidente que las opciones metodológicas condicionan los resultados de la investigación y, a este respecto, un cambio de metodología en la dirección de la ciencia ha hecho variar sustancialmente los resultados que hasta ahora venía ofreciendo la filosofia de la mente acerca de los eventos mentales. No se trata de fundarse en criterios de autoridad. Se trata de analizar El grado y la calidad de los argumentos procedentes de una y otra opción metodológica. Pues bien, a la vista de los conocimientos de los que hoy día dispone la neurobiología y la neurofisiología parece existir una mayor consistencia en los argumentos y demostraciones provenientes de la ciencia que en los que tienen lugar en el marco epistémico de la filosofía de la mente. Una perspectiva naturalista permite una explicación de la actividad mental y, de un modo especial de la conciencia, dentro del ámbito que le es propio. Salirse de este ámbito y situar los eventos mentales en un nivel de realidad diferente al natural, es viciar de raíz el origen biológico de cualquier actividad humana, incluida la actividad mental. Cuál es el funcionamiento de las estructuras físico-crebrales implicadas en esa actividad tan compleja como la actividad cognitiva, es algo que requiere 
todavía un largo recorrido y un esfuerzo de investigación considerable, pero no parece haber otro camino más correcto. Los fundamentos biológicos del comportamiento humano son algo evidente. La vida precede al pensamiento y a cualquier otra actividad humana. Las redes neurales y sus conexiones están a la base de todo comportamiento humano, incluida la actividad mental. El mismo Penrose dice que "tener una materia mental externa que no está sometida a leyes físicas es salirnos de algo que podría llamarse razonablamente una explicación científica ${ }^{75}$. Esta materia mental es, sin duda, el cerebro, en cuyas estructuras materiales y físicas hay que profundizar, al igual que hay que hacerlo en la estructura misma de la materia, cuya naturaleza y. leyes que la gobiernan hay que conocer si queremos finalmente explicarnos el origen de los seres conscientes ${ }^{76}$.

\section{Notas}

1 Penrose,T.: Las Sombras de la Mente. Crítica, Barcelona, 1996, p. 21.

2 Changeux,J. P. et Dehaene, St.: Modèles neuronaux des fonctions cognitives. (En Missa,J.N.- Philosophie de l'esprit et sciences du cerveau. Vrin, Paris, 1991, p. 68).

3 Dretske, F.: Naturalizing the mind. The MIT Press, Cambridge, 1995, pp. XIII-XIV.

4 ChURChland,P. S.: Les neurosciences concernet-elles la philosophie? (En MISSA, J. N.: Philosophie de l'esprit et sciences du cerveau. p. 22).

5 Stengers, I.: Et si demain le cerveau....? (En MisSA, J. N. o.c. pp. 147-161)

6 PenRose, R.: o.c. pp. 65-66.

7 MORA, F.(Ed.): El problema cerebro-mente. Alianza Universidad, Madrid, 1995. p. 266.

8 PAScual, R.: La fisica y la relación mente-cerebro (En MORA, F.(Ed.).: o.c. pp. 192-93 y 195.

9 Platon: Cratilo, 4006.

10 Los Filósofos Presocráticos. Edición preparada por AA.VV, Gredos, Madrid, 1990 , p. 295, n $^{\circ} 575$ y 576.

11 Epicure et les épicuriens. Textex choisis par J. Brun, PUF, Paris, 1978, p. 47, $\mathrm{n}^{\circ} 63$.

12 LuCRecio: De Rerum Natura. Bosch, Barcelona, 1985, p. 271.

13 ENGEL, P.: Psychologie populaire et explications scientifiques. (En MISSA, J.N.: o.c. pp.145-146).

14 ChurhCland, P.M. and Churchland, P.S.: Intertheoretic Reduction: a neuroscientist's Field Guide. (En WARNER, R and SzUBKA, T.: The mid-body problem. Blackwell, Oxford \& Cambridge, 1994, pp. 42-43).

15 Como señala F. Mora en su artículo Neurociencias: ¿Hacia una nueva concepción del hombre?, «el problema de la relación del cerebro con los procesos mentales es un problema que requiere de la multidisciplinariedad para alcanzar algún atisbo de entendimientow. Véase Revista Arbor, Febrero,1996, p. 170. 


\section{La naturalización de la mente}

16 ChURChland, P.M.: Eliminative Materialisme anthe propositional Attitudes. (En LyCAN,W.G.: Mind and Cognition. Basil Blackwell, Cambridge, 1990, p. 206).

17 Churchland, P.S.: A Perspective on Mind/Brain Research. En Journal of Philosophy. v. LXXVII, n. ${ }^{\circ}$, april, 1980. p. 186.

18 Véase Sejnoswski, T.J. and Churchland, P.S.: Brain and Cognition. (En Pos. NER, M.I.(Ed.): Foundations of cognitive science. The MIT Press, Cambridge, 1989, pp. 301-356).

19 Churchland, P.S. and SeJNowski, T.J.: Neural Representation and neural Computation. (En LYCAN, W.G.: o.c. pp. 248 y 250).

20 Churchland, P.M.: A Neurocomputational Perspective. The Nature of the structure of science. The MIT Press, Cambridge, 1989, p. 135.

21 GaRdner, H.: La nueva ciencia de la mente. Historia de la revolución cognitiva. Paidos, Buenos Aires, 1985, p. 312.

22 Dretske, F.: Mind and Brain. (En WARner, R. and SzuBKa, T.: o.c. p. 31).

23 Penrose, R.: o.c. p. 22.

24 MISSA, J.N.: L'esprit-cerveau. La philosophie de l'esprit à la lumière des neurosciences. Vrin, París, 1993, p. 38.

25 o.c. pp. 40-41.

26 Sejnowski, T.J. and Churchland, P.S.: Brain and Cognition (En Posner, M.I. (Ed.): o.c. p. 313).

27 Como señala L. Puelles, "la mente no nos es dada como un addendum (a modo de "software" inmaterial), sino que nuestras capacidades van emergiendo paso a paso a lo largo del proceso de desarrollo ontogenético cerebral y evolutivo animaln (PUELLES, L.: Desarrollo y plasticidad neurales. Implicacones para la teoría materialista emergente de la mente. Revista Arbor, Febrero 1996, p. 154).

28 ANDRIEU, B.: Eléments pour un matérialisme dynamique. Revue Philosophique de la France et de l'étranger, 1995, n. $^{\circ} 1$, janvier-mars, p. 8.

29 Churchland, P.M.: The Engine of Reason, the Seat of the Soul. The MIT Press, Cambridge, 1995, p. 203.

30 o.c. p. 203.

31 Churchland, P.C.: A Neurocomputational Perspective. The Nature of mind and the structure of science. pp. 130-132.

32 o.c. p. 131.

33 McCAuley, R.N. (Ed.).: The Churchlands and their Critics. Blackwell, Cambridge, 1996, p. 240.

34 McCauley, R.N. (Ed.): o.c. p. 297.

35 o.c. p. 297.

36 Churchland, P.M.: The Engine of Reason, the Seat of the Soul., p. 197.

37 o.c. p. 199.

38 o.c. p. 208.

39 o.c. p. 225.

40 McGINn, C.: Can we solve the mind-body problem. (En WARNER, R. and AZUBKA, T.: o.c. p. 102).

41 STRAWSON, S.: The experiential and the non-experiential. (En WARNER, R. and SzUBKA, T.: o.c. p. 74).

42 o.c. p. 76 .

43 WARNER, St.J.: Supervenience, Recognition and Consciousness. (En WARNER, R. and SzUBKa, T.: o.c. p. 88). 


\section{Jesús Martínez Velasco}

44 McGinn, C.: Can solve the mind-body problem? (En WARnER, R. and SzUBKA, T.: o.c. p. 110).

45 RORTY, R.: Consciousness, Intentionality and the Philosophy of mind (En WARNER, R. and SzUBKa, T.: o.c. p. 125).

46 Sejnowski, T.J. and Churchland, P.S.: Brain and Cognition. (En Posner, I.: o.c. p. 302 ).

47 o.c. p. 343.

48 o.c. p. 344.

49 RUMELHART, D.R.: The Architecture of mind. A connectionist approach. (En POSNER, E.(Ed): o.c. p. 135).

50 HURCHLAND, P.S. and SEJNOWSKI, T.J.: Neural Representation and Neural Computation. (En LYCAN, W.G. (Ed): o.c. p. 234).

51 Young, J.Z.: Philosophy and the Bran. Oxford University Press, Oxford, 1986. p. 8.

52 Churchland, P.S.: Véase el artículo citado: A Perspective on Mind/Brain Re-

search. En The Journal of Philosophy. v. LXXVII, $n^{\circ} 4$, april, 1980.

53 Como dice F. Mora, «a nadie se le escapa ya que el hombre, su mente y todo ese inmenso mundo de leyes y normas que rijen sus relaciones nacen de su cerebro" (MORA, F.: Neurociencias.....Revista Arbor, Febrero 1996, p. 164.

54 Como recuerda una vez más Mora, «entre estos dos niveles (la dinámica cerebral y los procesos mentales) no hay relación de CAUSACION». (MorA, F.: Neurociencias.... Revista Arbor, Febrero 1996, p. 171).

55 ChURCHLAND, P.S.: o.c. p. 207.

56 YOUNG, J.Z.: o.c. p. 19.

57 Véase Puelles, L.: Desarrollo y plasticidad neurales. En Revista Arbor, Febrero 1996, pp. 145-153, donde habla de los niveles de complejidad del sistema nervioso.

58 PENROSE, R.: o.c. p. 32.

59 Churchland, P.M.: Matter and Consciousness. The MIT Press, Cambridge, 1984, p. 140 .

60 Penrose, R.: o.c. p. 66.

61 o.c. p. 37 .

62 o.c. p. 50 .

63 o.c. p. 79 .

64 Churchland, P.M.: The Engine of Reason, the Seat of the Soul. p. 247.

65 PEnRose, R.: o.c. pp. 65-66. R.Pascual constata también, de un modo fehaciente, la dificultad de explicar científicamente los sistemas complejos. Ś́lo podemos describirlos y clasificarlos, pero poco sabemos, dice, de la globalidad de los mismos. Si resulta dificil explicar científicamente algunos sistemas simples, no es de extrañar que estemos todavía lejos de explicar racionalmente algunos aspectos siquiera parciales del funcionamiento de una estructura tan compleja como el cerebro. (PASCUAL, R.: La física y la relación mente-cerebro. En MORA, F.(Ed.): El problema cerebro-mente. p. 196). En cualquier caso, convenimos con él en que esto no debe ser obstáculo para que los sosprendentes comportamientos de los sistemas complejos no deban ser objeto de experimentación cuidadosa y de interpretación en términos científicos.

66 o.c. p. 414.

67 EccLes, J.: La Evolución del Cerebro. Creación de la Conciencia. Labor, Barcelona, 1992, p. 177.

68 PENROSE, R.: o.c. p. 433.

69 Eccles, J.: La Evolución del Cerebro. p. 179. 


\section{La naturalización de la mente}

70 Eccles, J.: Psique Humana. Tecnos, Madrid, 1986, p. 41.

71 Penrose, R.: o.c. p. 439

72 o.c. p. 440.

73 o.c. p. 442.

74 Churchland, P.M.: A Neurocomputational Perspertive. The Nature of Mind and the Structure of Science. p. XII.

75 o.c. p. 370.

76 o.c. pp. 371 y 441 . 